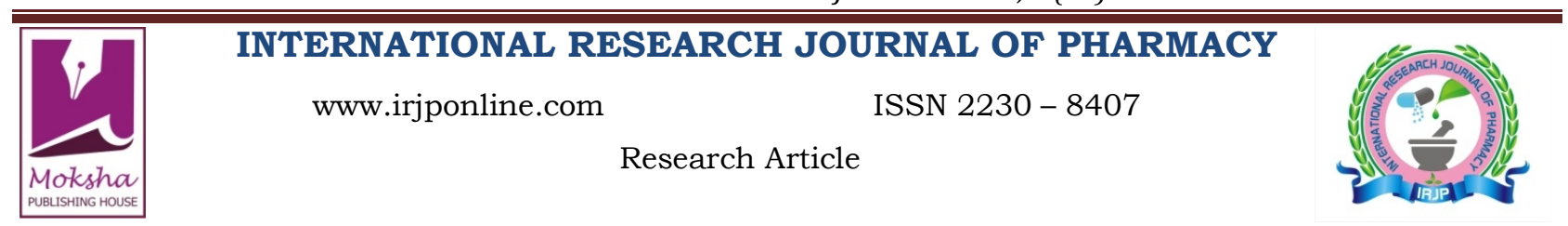

\title{
FORMULATION AND EVALUATION OF DENTAL GEL CONTAINING ESSENTIAL OIL OF CORIANDER AGAINST ORAL PATHOGENS
}

\author{
Pawar Vinita $\mathrm{A}^{1 *}$, Bhagat Trupti $\mathrm{B}^{1}$, Toshniwal Mitesh $\mathrm{R}^{1}$, Mokashi Nitin $\mathrm{D}^{2}$, Khandelwal K.R ${ }^{3}$ \\ ${ }^{1}$ Department of Pharmaceutics, JSPM'S Rajarshi Shahu College of Pharmacy and Research, Survey No. 80, Pune, Mumbai, \\ India \\ ${ }^{2}$ Depatment of Microbiology, Yashwantrao Chavan Memorial Hospital, Pimpri, Pune, (M.S), India \\ ${ }^{3}$ Principal, JSPM's Rajarshi Shahu College of Pharmacy and Research, Survey No. 80, Pune, Mumbai, India \\ *Corresponding Author Email: patole_vinita@yahoo.com
}

Article Received on: 20/08/13 Revised on: 21/09/13 Approved for publication: 17/10/13

DOI: $10.7897 / 2230-8407.041012$

IRJP is an official publication of Moksha Publishing House. Website: www.mokshaph.com

(C) All rights reserved.

\section{ABSTRACT}

The objective of this study was to investigate the antimicrobial potency of essential oil of Coriander against clinical samples isolated from the oral cavity of various patients and to formulate a suitable topical preparation containing Coriander oil. A total of 41 swabs were obtained from patients (age between $20-50$ years) which were diagnosed with oral infections like periodontal abscess, periapical abscess, chronic periodontities, periapical granuloma, dental caries, root caries and plaque samples. These samples were inoculated on Blood agar, Mac-conkeys agar and MRS Lactobacilli MRS agar, Mutans Sanguis agar, KF Streptococcal agar at $37^{\circ} \mathrm{C}$ for $24-48 \mathrm{~h}$ aerobically except for KF Streptococcal agar and Mutans Sanguis agar, which was incubated anaerobically at $37^{\circ} \mathrm{C}$ for $24-48 \mathrm{~h}$. The isolates were identified by standard microbiological procedures. The samples had positive cultures of Streptococcus faecalis, Streptococcus sanguis, Streptococcus oralis, Streptococcus mutans, Streptococcus salivarius, Lactobacilli, CONS. The susceptibility of these isolates was determined using agar disc diffusion method for zone of inhibition. The evaluation of antimicrobial potency was studied prior to gel formulation to compare the changes in activity after incorporation in polymer gel. The topical formulations were developed using different concentrations of polymers and evaluated for various physicochemical parameters like $\mathrm{pH}$, color, clarity, viscosity, consistency, homogeneity, spread ability. The activity of oil was not much affected by incorporation in gel. The gel showed promising antimicrobial activity against the strains used for the study.

Keywords: Essential oil, Coriander, Antimicrobial Activity, Gel, Disc Diffusion method, Zone of Inhibition, Periodontitis, Carbopol 934

\section{INTRODUCTION}

Local delivery of drugs to the tissues of the oral cavity has a number of applications including in the treatment of periodontal diseases like periodontal abscess, periapical abscess, chronic periodontities, periapical granuloma, dental caries, and root caries ${ }^{1}$. The word periodontal literally means "around the tooth". ${ }^{2}$. Periodontal disease broadly defines several diseases associated with the peridontium. In periodontal disease there is a formation of periodontal pocket which is pathologically deepened sulcus. In normal sulcus, the space between the teeth and gums is normally between 1 and $3 \mathrm{~mm}$ but in periodontitis the depth of pocket usually exceeds $5 \mathrm{~mm}$. Bacteria grow rapidly within periodontal pocket resulting in periodontal abscess. Gingivitis is inflammation of gingival caused by an accumulation of supra gingival plaque characterized by edema, erythema and light bleeding which is a moderate stage of periodontal disease. Periodontitis a more severe stage of periodontal disease in which the alveolar bone around the teeth is slowly and progressively lost and the periodontal ligaments supporting the tooth is detached resulting in the formation of periodontal pockets ${ }^{1}$. Dental caries also known as tooth decay or a cavity is an infection, bacterial in origin that causes demineralization and destruction of the hard tissues usually by production of acid by bacterial fermentation of food debris accumulated on the tooth surface ${ }^{3,4}$. Higher and aromatics plants have traditionally been used in folk medicine as well as to extend the shelf life of foods, showing inhibition against bacteria, fungi and yeasts ${ }^{5}$. Essential oils and extracts from several plant species are able to control microorganisms related to skin, dental caries and food spoilage, including Gram-negative and Gram-positive bacteria. Natural products have been recently investigated more thoroughly as promising agents for the prevention of oral diseases, especially plaque-related diseases such as dental caries ${ }^{6}$. During the past decade; the therapeutic use of herbal medicine is gaining considerable momentum in the world. The use of herbal medicine due to toxicity and side effects of allopathic medicines, has led to sudden increase in the number of herbal drug manufactures. Coriander (Coriandrum sativum L.) belonging to Apiaceae (Umbelliferae) family is a well-known herb widely used as a spice, in folk medicine. It is medicinally proved to have therapeutic activities like hypoglycemic, anti-inflammatory, hypolipidemic, antioxidant, anti-diabetic (Gray and Flatt, 1999) ${ }^{7}$ and anti microbial activity against bacteria and fungi. In addition, it is also used as carminative, diuretic, tonic, stimulant, stomachic, refrigerant, aphrodisiac and analgesic ${ }^{8}$.

\section{MATERIALS AND METHODS \\ Chemicals and Reagents \\ Essential oil}

Coriander essential oil was procured from-Shree Narayan Agro industries, India (commercial producer of plant essential oils and aromatic substances). As per manufacturer's information it was prepared by steam distillation. Carbopol 934 was obtained as gift sample from Emcure Pharmaceuticals, Pune, India. Methyl paraben, Propyl paraben, glycerin, propylene glycol were obtained from Merck Pvt. Ltd.

\section{Extraction of essential oil}

The dried Coriander seeds $(4 \mathrm{~kg})$ were coarsely powdered and submerged in ethanol $95 \%$ at room temperature for $12 \mathrm{~h}$. The extracts were then filtered through cheesecloth. The plant materials were submerged again in ethanol $95 \%$ for 3 days and filtered. The filtrates were then collected and evaporated using vacuum rotary evaporator at $50-60^{\circ} \mathrm{C}$. The concentrated 
extracts were dissolved in petroleum ether (AR grade) with boiling point of $40-60^{\circ} \mathrm{C}$ at room temperature and evaporated using vacuum rotary evaporator at $50-60^{\circ} \mathrm{C}$. The concentrated essential oils were then dissolved in ethanol $95 \%$ and stored at $4^{0} \mathrm{C}$ for further investigation ${ }^{9}$.

\section{Physicochemical characteristics of oils}

The essential oil of Coriander extracted in the laboratory was compared with the essential oil of Coriander procured from market with respect to physiochemical properties. The Coriander seed essential oil was analyzed for physicochemical characteristics namely refractive index $\left(25^{\circ} \mathrm{C}\right)$, density $\left(25^{\circ} \mathrm{C}\right)$, color, optical rotation $\left(25^{\circ} \mathrm{C}\right)$, solubility, acid number and ester number (Table 1) following AOAC standard methods (AOAC, 2012). The essential oils extracted from the laboratory and also procured from the market both were analyzed using gas chromatography from the Department of Chemistry, University of Pune, India to obtain their mass spectra and compare them (Figure 1).

\section{Collection of sample}

A total of 41 swabs samples from patients with oral infections like periodontal abscess, periapical abscess, chronic periodontities, periapical granuloma, dental caries, root caries attending the YCM Hospital, Pimpri, Pune, India were collected by trained personnel. Cotton swabs were first prepared and dipped in Cary and Blair transport medium in small tubes. Then, swabs along with medium in tubes were sterilized and then used for collection of samples. The swabs were gently pressed on the portion of teeth with caries and rotated 2-3 times. Then swabs were immediately dipped in the tube with sterile transport medium. The tubes were brought to Microbiology Laboratory of the Department of Microbiology, YCM Hospital, Pimpri, Pune, India for microbiological analysis ${ }^{3,4}$. The method of Cheesbrough (2000) was used for the microbiological analysis ${ }^{10}$. A loopful of each sample was inoculated on Blood agar, Mac-conkeys agar and MRS lactobacilli agar, Mutans Sanguis agar, KF Streptococcal agar at $37^{\circ} \mathrm{C}$ for $24-48 \mathrm{~h}$ aerobically except for KF Streptococcal agar and Mutans Sanguis agar in which the plates were incubated anaerobically. After incubation, macroscopic and microscopic examinations of colonies were carried out, sub-cultured on appropriate slants and stored at $37^{\circ} \mathrm{C}$ for biochemical and culture characterization for identification (Table 2).

\section{Identification of bacteria}

Isolated bacterial colonies were identified by using appropriate microscopic and macroscopic methods. The colony morphology and biochemical characteristics of the bacterial isolates were studied carefully (Cheesbrough $(2000)^{10}$. Gram staining was performed by preparing a thin homogenous bacterial smear on a clean glass slide from the bacterial culture grown on specific agar, air-dried and heatfixed. The smear was stained with crystal violet for 1 minute, washed with distilled water and flooded with Gram's iodine solution for 1 minute. The slide was again washed with water and decolorized with absolute alcohol until no violet color came off. The smear was counter stained with safranine for $30 \mathrm{sec}$, washed with water, blot-dried and observed under Microscope using oil immersion objective.

\section{Preparation of inoculums}

Inoculum was prepared by using isolated bacterial colonies. The bacterial colonies were inoculated in nutrient broth. All bacterial cultures were maintained by weekly transferring into nutrient broth and storing in sterile test tubes at low temperature.

\section{Inoculation of plates}

Muller Hinton agar plates were used. Muller Hinton agar was prepared and autoclaving at $121^{\circ} \mathrm{C}$ for 15 minutes was done. The medium was poured in sterile Petri plates under aseptic conditions. Then allowed the media to solidify at room temperature and stored at $4{ }^{\circ} \mathrm{C}$ until use. Inoculation of plates was done by the modified method of Acar and Goldstein using flood-inoculation technique ${ }^{11}$. A small single well isolated colony was emulsified in $2 \mathrm{ml}$ sterile saline in test tubes and the turbidity of the bacterial suspension was adjusted equivalent to $0.5 \mathrm{Mc}$ Farland and $2 \mathrm{ml}$ of this was transferred onto the Muller Hinton Agar plate and distributed gently over surface of medium with sterile glass spreaders to obtain uniform inoculums polysorbate $80(0.05 \%)$ was added to the agar base. The plates were dried for 5 minutes.

\section{Determination of antimicrobial activity}

Agar Disc diffusion method was used for screening of antimicrobial activity of Coriander oil ${ }^{12}$. The sterile filter paper discs of diameter $6 \mathrm{~mm}$ were impregnated with the test material $(20 \mu 1$ of Coriander oil) and aseptically placed on the inoculated plates. The plates were left at ambient temperature for 30 minutes to allow exceed pre diffusion prior to incubation at $37^{\circ} \mathrm{C}$ for $24 \mathrm{~h}$. The broad spectrum antibiotics i.e. Ampicilline was used as positive control for obtaining comparative results. Plates were observed after $24-48 \mathrm{~h}$ incubation for appearance of zones of inhibition around the discs (Table 3) (Figure 2, 3 and 4). Antibacterial activity was evaluated by measuring diameter of zones of inhibition (in millimeters) of bacterial growth.

\section{Determination of minimum inhibitory concentration}

The minimum inhibitory concentration (MIC) values were determined by agar dilution method ${ }^{12}$. The test materials were added aseptically to $20 \mathrm{ml}$ aliquots of sterile Muller Hilton agar (containing $0.05 \%$ polysorbate 80 ) at appropriate range of test material (1-5\% v/v for Coriander oil). The resulting agar solutions were vortexed at high speed until completely dispersed, immediately poured into sterile Petri plates then allowed to set for 30 minutes. The plates were then inoculated with the samples of Streptococcus faecalis, Streptococcus sanguis, Streptococcus oralis, Streptococcus mutans, Streptococcus salivarius, Lactobacilli acidophilus, CONS. for $24 \mathrm{~h}$ at $37^{\circ} \mathrm{C}$. Following the incubation period, the plates were observed and recorded for the presence or absence of growth. From the results, the MIC was recorded (Table 3) as the lowest concentration of test substance where the absence of growth was observed ${ }^{13,14}$.

\section{Preparation of gel}

Carbopol 934 gels were prepared by soaking Carbopol 934 in water and by neutralizing with triethanolamine to $\mathrm{pH} 6.4$. Weighed amount of methyl and propyl paraben were added to water prior to the addition of Carbopol 934. In another beaker the required quantity of propylene glycol was taken in another test tube to which accurately measured amount of Coriander oil corresponding to its MIC was incorporated and finally this mixture was added to the beaker containing carbopol with stirring. Sweetening agent was also added to the polymer dispersion and stirred continuously till it forms a homogeneous product. The volume was made up with 
distilled water and stirring was done vigorously. All the prepared gels were then subjected to evaluation tests in order to select the best formulation. The composition of different gel formulation is listed in (Table 4).

\section{Evaluation of gel formulation}

\section{Physical appearance}

The physical appearance of the formulation was checked visually.

- Color: The color of the formulations was checked out against white background.

- Consistency: The consistency was checked by applying on skin.

- Greasiness: The greasiness was assessed by the application on to the skin.

- Odor: The odor of the gels was checked by mixing the gel in water and taking the smell ${ }^{15,16}$.

\section{Determination of $\mathbf{p H}$}

The $\mathrm{pH}$ of gel was determined using digital $\mathrm{pH}$ meter by dipping the glass electrode completely into the gel system

\section{Determination of viscosity}

Viscosities of the formulated gels were determined using Brookfield Viscometer, spindle no. 7 and spindle speed 60 rpm at $25^{\circ} \mathrm{C}$ were used for gels, the corresponding dial reading on the viscometer was noted (Table 5)

\section{Determination of Spread ability}

Spread ability was determined by modified wooden block and glass slide apparatus. The apparatus consisted of a wooden block with fixed glass slide and a pulley. A pan was attached to another glass slide (movable) with the help of a string. For the determination of spread ability measured amount of gel was placed in the fixed glass slide, the movable glass slide with a pan attached to it, was placed over the fixed glass slide such that the gel was sandwiched between the two slides for 5 minutes. Now about $50 \mathrm{~g}$ of weight was added to the $\operatorname{pan}^{17}$. Time taken for the slides to separate was noted. Spread ability was determined using following formula:

$$
\mathrm{S}=\mathrm{M} . \mathrm{L} / \mathrm{T}
$$

Where $\mathrm{S}$ is the spread ability in $\mathrm{g} . \mathrm{cm} / \mathrm{s}, \mathrm{M}$ is the mass in grams and $\mathrm{T}$ is the time in seconds.

\section{Determination of Extrude ability}

It was determined by using a tube filled with the gel, having a tip of $5 \mathrm{~mm}$ opening and by measuring the amount of gel that extruded through the tip when a pressure was applied on the tube was noted down.

\section{Determination of Homogeneity}

All the developed gels were tested for homogeneity by visual inspection after the gels have been set in the container. They were tested for their appearance and presence of any aggregates.

\section{Determination of drug content}

The drug content of the gel formulations was determined by dissolving an accurately weighed quantity $1 \mathrm{~g}$ of gel in 100 $\mathrm{ml}$ of solvent (a mixture of ethanol and phosphate buffer $\mathrm{pH}$ $6.8(60: 40)$ for formulations of coriander oil). The solutions were kept for shaking for $4 \mathrm{~h}$ and then kept for $6 \mathrm{~h}$ for complete dissolution of the formulations. Then the solutions were filtered through $0.45 \mathrm{~mm}$ membrane filters and proper dilutions were made and solutions were subjected to the spectrophotometric analysis. The drug content was calculated from the linear regression equation obtained from the calibration data (Table 6) ${ }^{13}$.

\section{Antimicrobial Susceptibility test of gel}

The gels showing well accepted physicochemical properties and maximum drug content were finally selected for the antimicrobial assay in order to confirm whether any significant changes in the activity occurred after formulation. The solution of the gels was prepared and the anti bacterial activity was tested by Agar Disc diffusion method. A previously liquefied medium was inoculated with $0.2 \mathrm{ml}$ of bacterial suspension having a uniform turbidity. The culture medium $(20 \mathrm{ml})$ was poured into the sterile Petri dish. Care was taken for the uniform thickness of the layer of medium in different plates. After complete solidification of liquefied inoculated medium, the sterile filter paper discs of diameter $6 \mathrm{~mm}$ were impregnated with the test material and aseptically placed on the inoculated plates and the plates were left at ambient temperature for 30 minutes to allow pre diffusion prior to incubation at $37^{0} \mathrm{C}$ for $24 \mathrm{~h}$. After incubation period was over the antibacterial activity was estimated by measuring the diameter of the zone of inhibition. (Table 7)

\section{RESULT AND DISCUSSION}

\section{Physicochemical characteristics of oils}

The physicochemical properties can be used as a diagnostic criterion for evaluating the purity of the oils ${ }^{18}$. The essential oil of Coriander isolated in laboratory and procured from market was analyzed for physicochemical characteristics like color, odor, acid value, ester value, refractive index, optical rotation, density and solubility. The results obtained were comparable shown in (Table 1). The essential oils (both isolated and procured) were also analyzed by gas chromatography. Their mass spectra obtained was compared, it almost showed the same over lapping which confirmed the quality of the oil ascertained to be more than $80 \%$ pure (Figure 1). The results obtained from the physiochemical properties of essential oils and the analysis form gas chromatography studies revealed that there was no significant difference in the purity of oils isolated in laboratory and those procured from market. In the present work the essential oil of Coriander procured were used for further studies.

\section{Isolation and Identification of Bacteria}

Of the 41 swabs samples collected and examined from the oral cavity, the bacterial isolates which were identified included Streptococcus faecalis, Streptococcus sanguis, Streptococcus oralis, Streptococcus mutans, Streptococcus salivarius, Lactobacilli acidophilus, CONS. (Table 2)

\section{Antimicrobial activity assay of essential oil}

Coriander oil showed the antimicrobial activity against 3 bacterial isolates i.e. Streptococcus salivarius, Streptococcus sanguis, Lactobacilli and it was calculated in terms of inhibition zone diameter $(\mathrm{mm})$. The zone of inhibition was 25 $\pm 2.5 \mathrm{~mm}$ for Streptococcus salivarus, for Streptococcus sanguis was $20 \pm 2 \mathrm{~mm}$ and for Lactobacilli acidophilus was $19 \pm 3.2 \mathrm{~mm}$. It had shown MIC of $3.5 \% \mathrm{v} / \mathrm{v}$ for Streptococcus salivarus and $3.9 \% \mathrm{v} / \mathrm{v}$ for Streptococcus sanguis and $3.0 \% \mathrm{v} / \mathrm{v}$ for Lactobacilli (Table 3). 
Pawar Vinita A et al. Int. Res. J. Pharm. 2013, 4 (10)

\section{Table 1: Physicochemical Characteristics of Oils}

\begin{tabular}{|c|c|c|c|}
\hline S. No. & Parameters & Coriander oil extracted & Coriander oil Procured \\
\hline 1 & Color & Light Yellow & Light Yellow \\
\hline 2 & Odor & Aromatic & Aromatic \\
\hline 3 & Acid Value & 15.71 & 14.11 \\
\hline 4 & Ester Value & 15.36 & 16.36 \\
\hline 5 & Solubility in Ethanol & Freely Soluble & Freely Soluble \\
\hline 6 & Density & 0.83 & 0.85 \\
\hline 7 & Refractive index & 1.45 & 1.47 \\
\hline 8 & Optical Rotation & $+12^{0}$ & $+14^{0}$ \\
\hline
\end{tabular}

Table 2: Clinical Isolates Tested and their Sources

\begin{tabular}{|c|c|c|c|c|c|c|c|c|c|c|}
\hline \multirow{2}{*}{$\begin{array}{l}\text { S. } \\
\text { No }\end{array}$} & \multirow{2}{*}{$\begin{array}{c}\text { Name of Bacteria } \\
\text { (Bacterial Isolates) }\end{array}$} & \multirow[t]{2}{*}{ Gram Staining } & \multicolumn{8}{|c|}{ Source and number of strains tested } \\
\hline & & & $\begin{array}{c}\begin{array}{c}\text { Periapical } \\
\text { abscess }\end{array} \\
\end{array}$ & $\begin{array}{c}\text { Necrotic Pulp tissue } \\
\text { from caries }\end{array}$ & $\begin{array}{c}\text { Chronic } \\
\text { periodontitis }\end{array}$ & $\begin{array}{l}\text { Dental } \\
\text { caries }\end{array}$ & $\begin{array}{r}\text { Periapical } \\
\text { granuloma }\end{array}$ & $\begin{array}{c}\text { Root } \\
\text { caries }\end{array}$ & $\begin{array}{c}\text { Others } \\
\#\end{array}$ & Total \\
\hline 1 & Streptococcus oralis & GPC & 01 & - & - & 02 & - & - & 02 & 05 \\
\hline 2 & $\begin{array}{l}\text { Streptococcus } \\
\text { faecalis }\end{array}$ & GPC & - & - & - & 02 & - & 01 & 03 & 06 \\
\hline 3 & $\begin{array}{c}\text { Streptococcus } \\
\text { salivarius }\end{array}$ & GPC & 01 & 01 & - & - & - & - & 01 & 03 \\
\hline 4 & $\begin{array}{c}\text { Streptococcus } \\
\text { mutans }\end{array}$ & GPC & 01 & - & - & 03 & - & - & 04 & 08 \\
\hline 5 & $\begin{array}{l}\text { Streptococcus } \\
\text { sanguis } \\
\end{array}$ & GPC & - & - & - & - & - & 01 & 02 & 03 \\
\hline 6 & CONS* & GPC & - & - & 01 & 01 & - & - & 01 & 03 \\
\hline 7 & $\begin{array}{l}\text { Lactobacilli } \\
\text { acidophilus }\end{array}$ & GPB & - & - & - & 01 & - & 02 & 01 & 04 \\
\hline 8 & Candida species & $\begin{array}{c}\text { GPC in } \\
\text { budding yeast }\end{array}$ & & - & - & 01 & 01 & 01 & 01 & 04 \\
\hline
\end{tabular}

\#Other sources: - salivary sample, plaque sample, sub gingival specimen, pulp tissue granulation tissue, calculus infected wound *CONS: - Coagulase Negative Staphylococcus

Table 3: Effect of Coriander Oil against Sensitive Strains of Bacteria

\begin{tabular}{|c|c|c|}
\hline Name of sensitive strains & Zone of inhibition & (MIC) \\
\hline Streptococcus salivarius & $25 \pm 2.5$ & $3.5 \% \mathrm{v} / \mathrm{v}$ \\
\hline Streptococcus sanguis & $20 \pm 2$ & $3.9 \% \mathrm{v} / \mathrm{V}$ \\
\hline Lactobacilli acidophilus & $19 \pm 3.2$ & $3.0 \% \mathrm{~V} / \mathrm{v}$ \\
\hline
\end{tabular}

Table 4: Composition of Gel Formulation

\begin{tabular}{|c|c|c|c|c|c|c|c|c|c|}
\hline Ingredients & F1 & F2 & F3 & F4 & F5 & F6 & F7 & F8 & F1 \\
\hline Coriander oil (ml) & 0.75 & 0.75 & 0.75 & 0.75 & 0.75 & 0.75 & 0.75 & 0.75 & 0.75 \\
\hline Carbopol 934 (g) & 0.3 & 0.4 & 0.5 & 0.6 & 1.7 & 1.8 & 1.9 & 1 & 0.3 \\
\hline Propylene Glycol (ml) & 15 & 15 & 15 & 15 & 15 & 15 & 15 & 15 & 15 \\
\hline Glycerin (ml) & 5 & 5 & 5 & 5 & 5 & 5 & 5 & 5 & 5 \\
\hline Methyl Paraben (g) & 0.18 & 0.18 & 0.18 & 0.18 & 0.18 & 0.18 & 0.18 & 0.18 & 0.18 \\
\hline Propyl Paraben(g) & 0.02 & 0.02 & 0.02 & 0.02 & 0.02 & 0.02 & 0.02 & 0.02 & 0.02 \\
\hline Aspartame (g) & 0.4 & 0.4 & 0.4 & 0.4 & 0.4 & 0.4 & 0.4 & 0.4 & 0.4 \\
\hline Distilled Water & q.s & q.s & q.s & q.s & q.s & q.s & q.s & q.s & q.s \\
\hline
\end{tabular}

Table 5: Characteristics of Gel Formulation

\begin{tabular}{|c|c|c|c|c|c|c|}
\hline Formulation & Appearance & $\mathbf{p H}$ & Viscosity (cps) & Spread ability (g-cm/sec) & Tube Exrutability (\%) & Homogeneity \\
\hline F1 & Pale yellow & 6.7 & 41280 & 18.22 & 92.16 & Good \\
\hline F2 & Pale yellow & 6.8 & 41660 & 18.16 & 94.15 & Good \\
\hline F3 & Pale yellow & 6.8 & 42380 & 17.52 & 95.1 & Very good \\
\hline F4 & Pale yellow & 6.7 & 42426 & 16.74 & 89.23 & Good \\
\hline F5 & Pale yellow & 6.9 & 43160 & 15.32 & 90.00 & Good \\
\hline F6 & Pale yellow & 6.8 & 44842 & 15.98 & Good \\
\hline F7 & Pale yellow & 6.5 & 45180 & 15.91 & Good & 89.2 \\
\hline F8 & Pale yellow & 6.4 & 45412 & 15.62 & Very good \\
\hline
\end{tabular}

Table 6: Drug Content of Formulation

\begin{tabular}{|c|c|}
\hline Formulations & Drug Content\% \\
\hline F1 & 95 \\
\hline F2 & 95.3 \\
\hline F3 & 95.5 \\
\hline F4 & 93.65 \\
\hline F5 & 92.69 \\
\hline F6 & 91.3 \\
\hline F7 & 90.23 \\
\hline F8 & 89.10 \\
\hline
\end{tabular}


Pawar Vinita A et al. Int. Res. J. Pharm. 2013, 4 (10)

Table 7: Antimicrobial Activity of Formulation of Coriander Oil

\begin{tabular}{|c|c|c|c|c|c|}
\hline Micro-organisms & $\begin{array}{c}\text { Zone of inhibition in } \\
\text { mm (F2) }\end{array}$ & $\begin{array}{c}\text { Zone of inhibition in } \\
\mathbf{m m} \text { (F3) }\end{array}$ & $\begin{array}{c}\text { Ampicillin } \\
\text { (Std) }\end{array}$ & $\begin{array}{c}\text { Tetracycline } \\
\text { (Std) }\end{array}$ & $\begin{array}{c}\text { Zone of inhibition } \\
\text { in mm (F2) }\end{array}$ \\
\hline S. salivarius & $23 \pm 2.6$ & $24 \pm 1.2$ & $20 \pm 1.6$ & $40 \pm 1.2$ & $23 \pm 2.6$ \\
\hline S. sanguis & $18 \pm 4.2$ & $20 \pm 1.3$ & $21 \pm 1.3$ & $36 \pm 3.5$ & $18 \pm 4.2$ \\
\hline L.acidophilus & $18 \pm 1.9$ & $19 \pm 2.9$ & $12 \pm 2.2$ & $30 \pm 2.4$ & $18 \pm 1.9$ \\
\hline
\end{tabular}

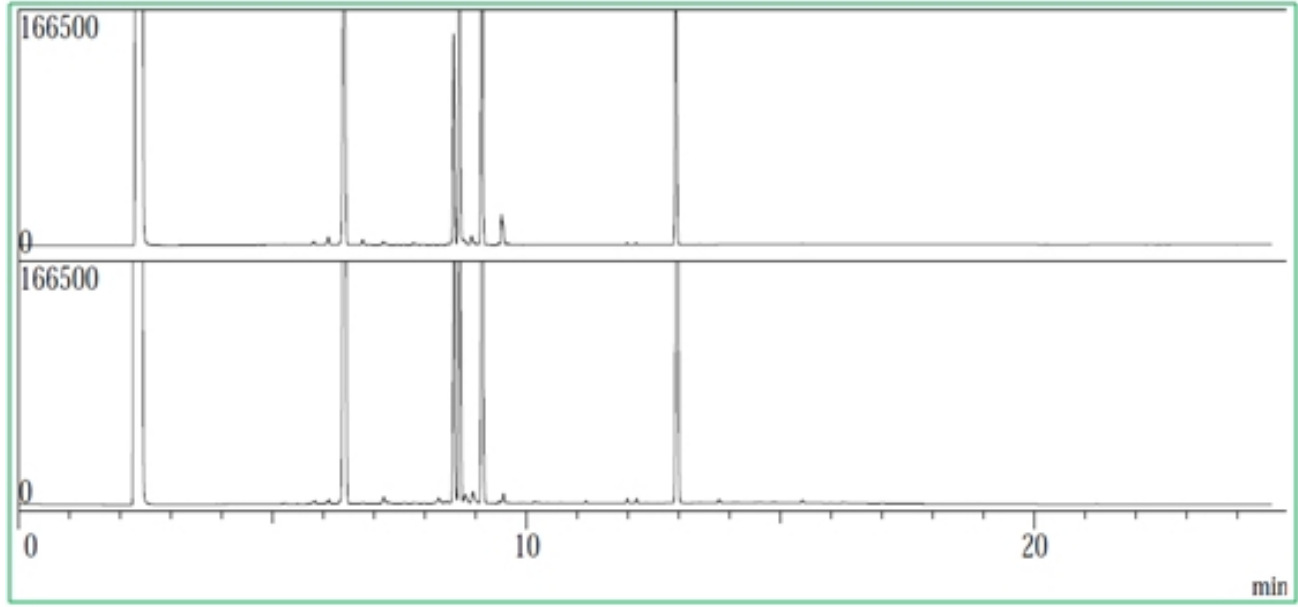

A: - Coriander Essential Oil Procured

B: - Coriander Essential Oil Isolated

Figure 1: Gas Chromatograms of Coriander Seed Oil

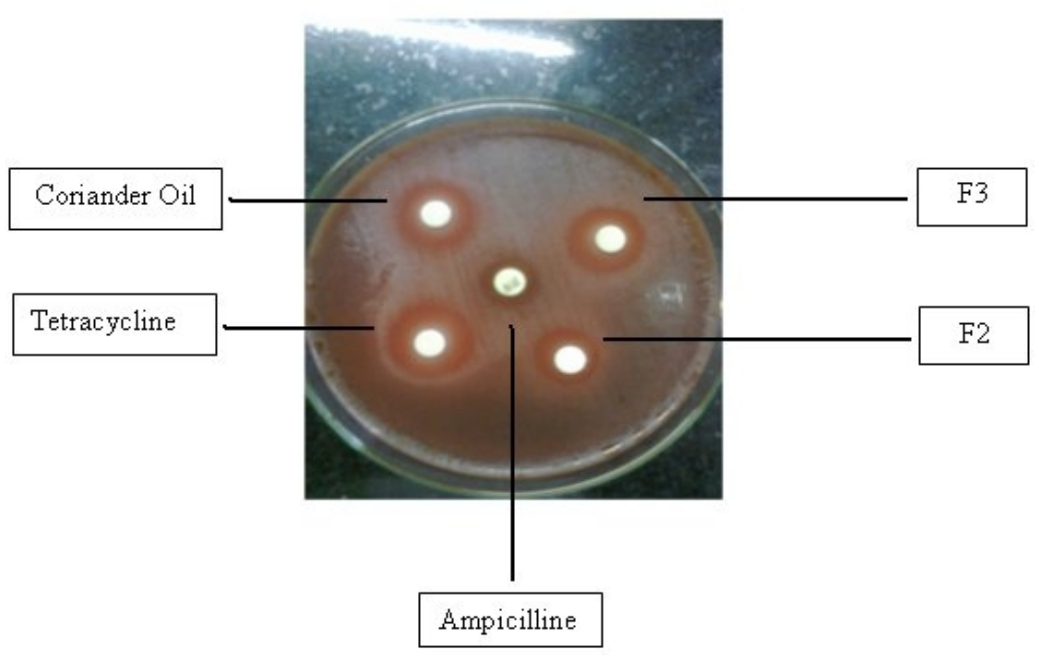

Figure 2: Zone of Inhibition for $S$. salivarius

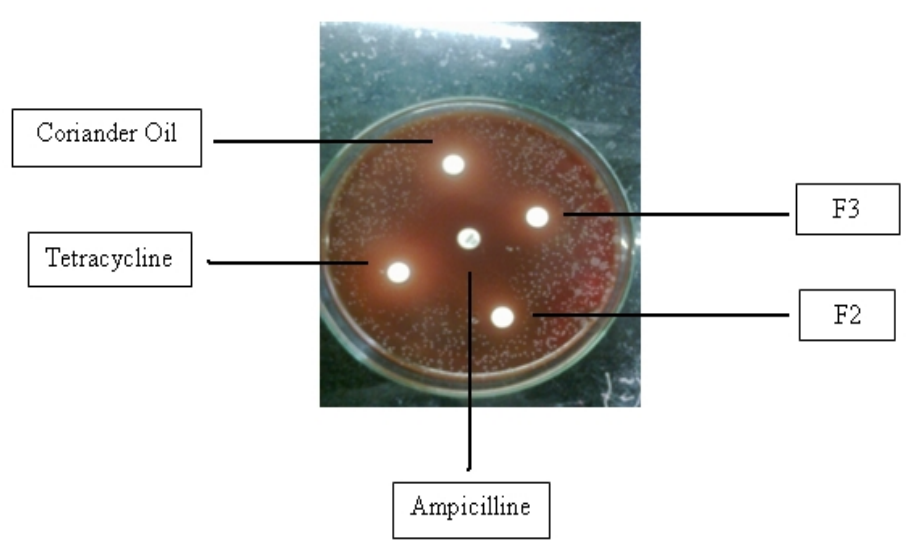

Figure 3: Zone of Inhibition for $S$. sanguis 


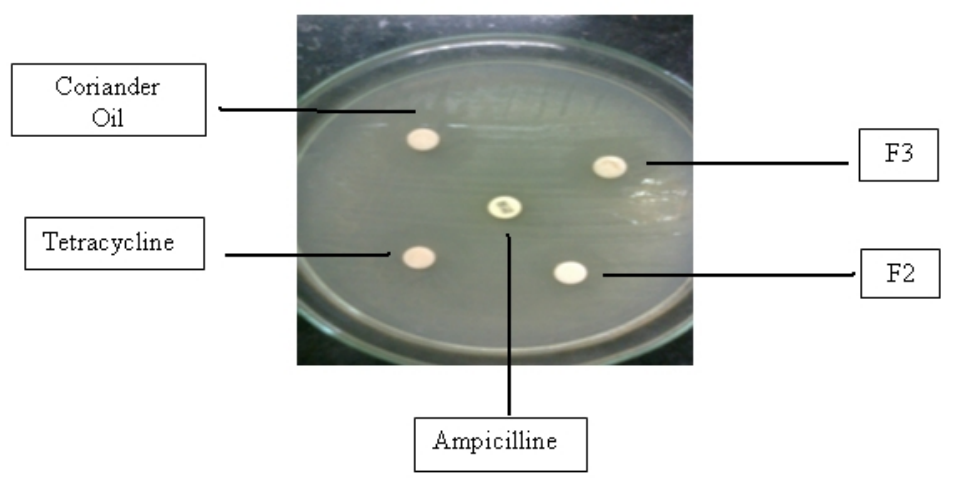

Figure 4: Zone of Inhibition for $L$. acidophilus

\section{Preparation of gel formulation}

The oral gel formulation of Coriander oil was developed with Carbopol 934. Formulation Composition is given in (Table 4). All the eight batches of formulations were evaluated for physical properties. All the formulations were pale yellow in color and had characteristic odor of Coriander oil. The $\mathrm{pH}$ for all formulations ranged from 6.4 - 6.9, which was well within the normal $\mathrm{pH}$ range of buccal cavity 6 to 7 , which substantiates that the prepared gels will be irritation free ${ }^{1}$. The viscosities of the formulations ranged from $41280 \mathrm{cps}$ to 45412 cps shown in (Table 5). The spread ability of the gels was found to be in the range of $15.32-18.22 \mathrm{~g}-\mathrm{cm} / \mathrm{sec}$, conforming that the gels may spread smoothly and uniformly. The formulations with the highest viscosity had the minimum spread ability and vice-versa ${ }^{17}$. The formulations were glossy and translucent. The homogeneity of all formulations was good. Tube extrude ability of the gels was good. The gel was passable through the tube and its value decreased with an increase in viscosity.

\section{Drug Content}

The drug content of the formulations ranged from $89.10 \%$ to $95.5 \%$ (Table 6). From the values obtained from the drug content it was concluded that there was no degradation of drug during the preparation process. The formulation F3 was found to have maximum drug content.

\section{Antimicrobial efficacy studies of gel formulation}

The gel formulations of Coriander oil F2 and F3 showed good physicochemical properties as well as good drug content compared to other formulation (Table 5, 6). Hence these formulations were further selected for antimicrobial studies. The results of antimicrobial studies showed that gel formulation of Coriander oil F3 showed maximum zone of inhibition (Table 7). The diameter of zone of inhibition shown by the formulation F3 was similar to that of crude oil which is in agreement with the fact that incorporation of drug into gel base does not decrease its antibacterial activity.

\section{CONCLUSION}

The Coriander oil was found to have antibacterial activity against Streptococcus salivarius, Streptococcus sanguis and Lactobacilli acidophilus. The formulations developed from coriander showed significant results so it can be further used commercially to develop dental gels after conducting clinical trials on human beings. Nevertheless further research is still needed in order to determine if they efficiently could substitute the synthetic antibiotics or used in combination.

\section{ACKNOWLEDGEMENT}

The authors are thankful to the Principal, Dr. K R. Khandelwal for providing necessary infrastructure and all facilities required for carrying out the project. We would also like to acknowledge and express obligations to Dr. Supriya Kheur, Dr. D.Y. Patil Dental Hospital, Pimpri, Pune, India.

\section{REFERENCES}

1. Devi S, Basavaraj BV, Bharath S, Deveswaran R and Madhavan V. Antimicrobial studies of extended release amoxicillin trihydrate dental gels. Der Pharmacia Lettre 2012; 4(1): 275-286.

2. Yellanki SA, Singh J and Manvi FV. Formulation, Characterization and Evaluation of Metronidazole gel for local treatment of periodontitis. International Journal of Pharm and Bio Sciences 2010; 2: 1-9.

3. Botelho MA, Nogueira AP, Bastos GM, Fonseca SGC et al. Antimicrobial activity of the essential oil from Lippia sidoides, carvacrol and thymol against oral pathogens. Brazilian Journal of Medical and Biological Research 2007; 40: 349-356. http://dx.doi.org/10.1590/ S0100-879X2007000300010 PMid: 17334532

4. Javed B Mulla. A study in between dental cavity and diabetes mellitus With reference to macro- minerals elements in Indian adults. International Journal of Basic and Applied Medical Sciences 2013; 3(1): $170-175$.

5. Sartoretto A, Lúcia MA, Delarmelina $\mathrm{C}$ et al. Composition and antimicrobial activity of essential oils from aromatic plants used in Brazil. Brazilian Journal of Microbiology 2004; 35: 275-280. http://dx.doi.org/10.1590/S1517-83822004000300001

6. Pai MR, Acharya LD, Kapur N. Evaluation of anti plaque activity of Azadirachta indica Leaf extract gel - a 6-week clinical study. J Ethnopharmacol 2004; 90: 99-103. http://dx.doi.org/10.1016/ j.jep.2003.09.035 PMid:14698516

7. Gray AM, Flatt PR. Insulin-releasing and insulin-like activity of the traditional anti-diabetic plant Coriandrum sativum (coriander). Br J Nutr 1999; 81(3): 203-209. http://dx.doi.org/10.1017/S0007114599000392

8. Masood N, Chaudhry A, Tariq P. Original article bactericidal activity of black pepper, bay leaf, aniseed and coriander against oral isolates. Pak. J. Pharm Sci 2006; 19(3): 214-218.

9. Thanaboripat D, Suvathi Y, Srilohasin P et al. Inhibitory effect of essential oils on the growth of Aspergillus flavus. KMITL Sci. Tech. J 2007; 7: 1-7.

10. Monica Cheesbrough. District Laboratory Practice in Tropical Countries Part 2 Second Editions; 2000. p. 35-79.

11. Acar JF and FW. Goldstein: Disk Susceptibility Test. In: Antibiotics in Laboratory Medicine Fourth Edition. William and Wilkins Co. Baltimore; 1996. p. 1-51.

12. Eucast: Disk diffusion method for antimicrobial susceptibility testingversion $1.0 ; 2009$.

13. Vats A, Sharma P. Formulation and evaluation of topical anti acne formulation of coriander oil. International Journal of Pharmacy and Pharmaceutical Science Research 2012; 2(3): 61-66.

14. European Committee for Antimicrobial Susceptibility Testing (EUCAST); Determination of minimum inhibitory concentrations (MICs) of antibacterial agents by agar dilution. Definitive Document E. Def $3.1 ; 2000$.

15. Pandey A, Jagtap J, Polshettiwar SA. Formulation and evaluation of in vitro antimicrobial activity of gel containing essential oils and effect of polymer on their antimicrobial activity. International Journal of Pharmacy and Pharmaceutical Sciences 2011; 3(1): 234-237.

16. Satpathy B, Sahoo M, Sahoo P, Patra SR. Formulation and evaluation of gel containing essential oils of Piper betle against skin infection pathogens. Int. J. Res Phar. Sci 2011; 2(3): 373-378. 
17. Mitra J, Mohammad RR, Hedayte S. Mucoadhesive and drug release properties of benzocaine gel. Iranian J. Pharm. Sci 2006; 2: 185-94.

18. Anwar F, Sulman M, Hussain AI, nazamid et al. Physicochemical composition of hydro-distilled essential oil from Coriander (Coriandrum sativum 1.) seed cultivated in Pakistan. Journal of Medicinal Plants Research 2011; 5(15): 3537-3544.

19. Preuss Hg, Echard B, Dadgar A, Talpur N, Manohar V, Enig M, et al. Effects of essential oil and monolaurin on Staphylococcus aureus: in vitro and in vivo studies. Toxical Mech Methods 2005; 15: 279-85. http://dx.doi.org/10.1080/15376520590968833 PMid:20021093
20. Alexopoulos A, Kimbaris S, Plessas et al. Antimicrobial activities of essential oils from eight Greek aromatic plants against clinical isolates of Staphylococcus aureus. Anaerobe 2011; 17: 399-402. http://dx.doi. org/10.1016/j.anaerobe.2011.03.024 PMid:21521657

Cite this article as:

Pawar Vinita A, Bhagat Trupti B, Toshniwal Mitesh R, Mokashi Nitin D,

Khandelwal K.R. Formulation and evaluation of dental gel containing essential oil of coriander against oral pathogens. Int. Res. J. Pharm. 2013; 4(10):48-54 http://dx.doi.org/10.7897/2230-8407.041012 